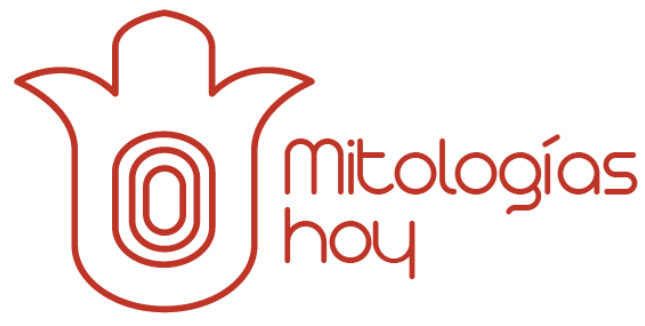

\title{
CULTURA Y REVOLUCIÓN. TRES NOTAS A PROPÓSITO DE MEMORIAS DEL SUBDESARROLLO*
}

Three notes on Memories of underdevelopment

JORGE FORNET

Casa de las Américas (Cuba)

direccioncil@casa.cult.cu

https://orcid.org/0000-0003-0697-0756

DOI: https://doi.org/10.5565/rev/mitologias.828

vol. 24 | noviembre 2021 | 73-85

Recibido: 29/09/2021 | Aceptado: 07/10/2021

\section{Resumen}

Más allá de la multitud de interpretaciones que han generado las versiones literaria y cinematográfica de Memorias del subdesarrollo, estas tres notas pretenden acercarse al modo en que dichas versiones se insertan y hasta cierto punto resuelven conflictos planteados al intelectual cubano en la Revolución. La polémica en torno a la prohibición de P.M., la influencia de la figura de Ernest Hemingway entre los escritores de la Isla y el papel de un autor atípico y de un texto menor en la configuración del protagonista de Memorias... permiten vislumbrar el modo en que la literatura y el cine cubanos abordan temas como la censura, la figura y el papel del intelectual o la configuración de políticas culturales en épocas de inflexión histórica.

\footnotetext{
* Este texto forma parte de un estudio sobre el campo cultural cubano en los años iniciales de la Revolución.
} 


\title{
Palabras clave
}

Edmundo Desnoes, Tomás Gutiérrez Alea, Memorias del subdesarrollo, P.M., política cultural, relación intelectual-Revolución

\begin{abstract}
Beyond the multitude of interpretations that have generated the novel Inconsolable Memories and its film version Memories of underdevelopment, these three notes are intended to approach the way in which such versions are inserted and to some extent resolve conflicts raised to the Cuban intellectual in the Revolution. The controversy surrounding the ban of the short film P.M., the influence of the figure of Ernest Hemingway among the writers of the Island and the role of an atypical author and of a minor text in the configuration of the protagonist of Memories... allow us to glimpse the way in which Cuban literature and cinema approach topics such as censorship, the figure and role of the intellectual or the configuration of policies cultural in times of historical inflection.
\end{abstract}

\section{Keywords}

Edmundo Desnoes, Tomás Gutiérrez Alea, Memories of underdevelopment, P.M., cultural politics, relationship intelectual-revolution

\section{Uno}

En el principio fue la polémica. Precedida por discrepancias de larga data, tanto personales como estéticas e ideológicas, entre intelectuales que apoyaron de manera activa el triunfo revolucionario, el verdadero punto de inflexión fue la prohibición del documental P.M. en mayo de 1961. Un acuerdo del Instituto Cubano de Arte e Industria Cinematográficos (ICAIC) sobre la película hizo explícita la decisión de "prohibir su exhibición, por ofrecer una pintura parcial de la vida nocturna habanera, que empobrece, desfigura y desvirtúa la actitud que mantiene el pueblo cubano contra los ataques arteros de la contrarrevolución a las órdenes del imperialismo yanki" (Luis, 2003: 223). La historia es conocida y ha sido ampliamente comentada en una abundante bibliografía que no cesa de crecer.

Me limito aquí a recordar que a partir de ese momento el ambiente se enrareció, y pasaron a un primer plano diferencias que ponían en evidencia la heterogeneidad de intereses y tendencias que hasta entonces habían convivido de manera más o menos pacífica al interior del campo cultural cubano. Particularmente agudas, como se sabe, fueron las pugnas entre el periódico Revolución y su suplemento Lunes de Revolución, dirigidos respectivamente por Carlos Franqui y Guillermo Cabrera Infante, de un lado; y el Icaic, presidido por Alfredo Guevara, del otro. El hecho es que la censura desató un alud de especulaciones e hizo aflorar preocupaciones latentes, entre las cuales el temor a un posible proceso de estalinización no era la menor. Estaba previsto celebrar en la última semana del mes de junio de aquel año el Primer Congreso Nacional de Escritores y Artistas de Cuba, algo imposible en el erizado clima del momento, por lo que dicho encuentro sería pospuesto (se celebraría, finalmente, en el mes de agosto) y 
precedido por tres largas reuniones en la Biblioteca Nacional de parte de la intelectualidad con las autoridades políticas y culturales del país, que concluyó en las célebres "Palabras a los intelectuales" pronunciadas por el entonces Primer Ministro Fidel Castro.

Si he hecho este preámbulo es simplemente para recordar el punto de partida, pero lo que en verdad me interesa ver, para comenzar, es el modo en que Memorias del subdesarrollo, tanto la novela de Edmundo Desnoes, de 1965, como — sobre todo— la película de Tomás Gutiérrez Alea, de 1968, se incorporaron tardía y tangencialmente a la polémica desatada en torno a P.M., un intento de retomar de manera velada el capítulo abierto por el corto dirigido por Sabá Cabrera Infante y Orlando Jiménez Leal. ${ }^{1}$ Me permito, por cierto, abordar la novela y la película como un solo texto bicéfalo, no solo porque existen ya precedentes sino también porque como reconoció el novelista en un "Epílogo para la gente nueva" incluido en la edición cubana de 2003: "A Titón [Gutiérrez Alea] debo el milagro de la profunda visualización de mis palabras. Creo que no existe en toda la historia del cine una colaboración más estrecha y fecunda que la que existió entre nosotros. Hoy la novela y la película son una y la misma cosa" (Desnoes, 2003: 130). ${ }^{2}$

Para entender la posición de Memorias... ante el conflicto suscitado por P.M., es útil conocer someramente las discrepancias, en ese período, entre Guevara y Gutiérrez Alea, antiguos amigos y fundadores ambos del Icaic. Durante la primera sesión de los diálogos en la Biblioteca Nacional, el viernes 16 de junio de 1961, Alea fue uno de los primeros en intervenir y, al menos en principio, pareció alinearse con la postura oficial del Icaic y del Consejo Nacional de Cultura. Es decir, aceptó que "quizás se hayan cometido errores en el estilo de tratar este asunto" de la prohibición, y descartó que se tratara de una película contrarrevolucionaria, pero le reprochó que, "al tocar un aspecto de la realidad, no lo toca en una forma debida y, por lo tanto, dice una mentira de la manera más hipócrita que se pueda decir, que es ocultando una parte de la verdad". Si bien le reconoció valores artísticos y como documento, resultaba inoportuna, "y sería realmente malo, realmente muy malo, que esa película fuera a caer en manos de gente que fuera a utilizarla contra nosotros. Estaríamos dándole un arma al enemigo, cosa que no hay por qué hacer ahora". Si hasta ahí Alea no dijo nada que no coincidiera con quienes defendían la prohibición, pronto deslizaría "otro problema que es muy interesante, y [...] quisiera dejarlo planteado. Es el problema de la excesiva centralización de organismos que se dedican a la creación artística". Y remarcó entonces que con "una excesiva centralización de organismos de creación artística, corremos el peligro de que una sola tendencia sea la que pueda servir dentro de un medio. Y a lo mejor estamos evitando que supervivan otras tendencias que pueden ser igualmente valiosas" (Paz, 2021: 117).

El desacuerdo que ahí se insinúa, no era nuevo. Dos semanas antes, el 3 de junio, Alea había formalizado ante el Consejo Directivo del ICAIC su decisión de renunciar al cargo de Consejero de ese Instituto, que ostentaba desde la fundación del organismo en marzo de 1959. A raíz de la polémica en torno a P.M. y la forma en que se llevó a cabo su prohibición, el ICAIC redactó un comunicado oficial que fue leído antes de la proyección de la película a un grupo de miembros de la Asociación de Artistas y Escritores. Más allá de su acuerdo o no con el documento, el cineasta expresaba que se debió contar con él para su redacción y darle a conocer la postura oficial del ICAIC; sin embargo, afirma, "fui excluido de las discusiones donde se trató el problema del comunicado y se definió la política a seguir" (Gutiérrez Alea, 2007: 75). Ya antes había escrito también un duro "Memorando" dirigido a Alfredo Guevara, con

\footnotetext{
${ }^{1}$ La idea de que Memorias... fue un intento por cerrar el capítulo abierto por $P M$, la expuse por primera vez en "Instantáneas o ¿para que sirven los jarrones del Palacio de Invierno?”, aparecido en La Gaceta de Cuba núm. 4 de 2004.

2 Aunque utilizo la edición de 2003, la más reciente que conozco de la novela, es bien sabido que ella ha sufrido varios cambios desde su aparición, y que la propia película enriqueció esas sucesivas versiones. Un análisis de esas metamorfosis puede encontrarse en Enrico Mario Santí, para quien "no tiene sentido hablar de 'la novela de Desnoes'como si ésta fuera un solo texto" (Santí, 2002: 279). Por si fuera poco, tras la publicación del guion de la película en 2017, el cual muestra algunas notables diferencias en relación tanto con la novela como con la película, debería incorporársele a futuros acercamientos (y hablaríamos entonces, al menos, de un texto tricéfalo). Me abstengo, por el momento, de incluir el guion en el análisis.
} 
fecha de 25 de mayo de 1961, denunciando la "dirección unipersonal" del ICAIC, (2007: 88), y toda una serie de razones de semejante tenor por las cuales "no puedo solidarizarme con la política que se ha mantenido hasta ahora en el Instituto" (2007: 89).

Alfredo Guevara, por su parte, arremetió en un Consejo de Dirección del ICAIC no ya contra el grupo de Lunes, sino contra el propio Alea. Afirmaba sentir una profunda contradicción ideológica "con el compañero Titón", a quien caracterizaba como alguien que "baila al son de la música que toca el enemigo", "no tiene defensas frente a las posiciones ideológicas del grupo" de Lunes y "está muy cerca de ser el más honesto de [sus] miembros" (2003: 96). En los primeros días de julio se celebró, con la presencia de ambos, una reunión extraordinaria del grupo de dirección del ICAIC y miembros de la fracción del Partido Socialista Popular del Instituto, en que volvieron a aflorar las profundas diferencias entre ellos. ${ }^{3}$ Aunque la relación entre ambos fue zigzagueante $-\mathrm{y}$ tendía al acercamiento frente a enemigos comunes, como ocurrió en 1963 ante los ataques al ICAIC por parte de las posiciones más conservadoras del periódico Hoy, encarnadas en Blas Roca, su director-, en general fueron distantes, cuando no hostiles.

Todo ello forma parte del sustrato sobre el que se sostiene Memorias del subdesarrollo, incluida su pretensión de incorporarse tardíamente a la polémica de 1961. Para empezar, hay zonas del largometraje que remiten a la atmósfera del corto, acentuada por una estética cercana en ocasiones al free-cinema, utilizada por P.M., y que fuera defendida y vapuleada con similar pasión durante las discusiones de aquel año. No es casual que eso saltara a la vista de algunos espectadores. Jiménez Leal, quien vio la película de Alea en una proyección que tuvo lugar en Nueva York, le contaría a su amigo Jaime Soriano (quien a su vez se lo escribiría a Guillermo Cabrera Infante en una carta de julio de 1971) que cuando la película empieza "se va descubriendo un panorama absolutamente espectral de una ciudad y una sociedad en descomposición, con una sinceridad y una objetividad que resultan inconcebibles en aquel medio, como si el fantasma de P.M. regresara de la tumba" (Soriano, 2018: 276). Es, obviamente, una lectura bastante peculiar e interesada del filme, pero la evocación de P.M. no es descabellada.

Memorias del subdesarrollo transcurre en los meses especialmente convulsos que median entre la batalla y triunfo de Playa Girón y la Crisis de Octubre, de manera que reproduce la situación en que surgió el documental y que dio pie a uno de los principales argumentos de sus detractores: interesarse por ese ambiente de disipación en medio de una situación de gran peligro para el país. En verdad, la perspectiva de Memorias... elude lo festivo. El hecho de estar contadas — tanto la novela como la película - desde la subjetividad de un personaje que se resiste a involucrarse en eso que suele llamarse la marea de la historia, condiciona la mirada. El protagonista (que en la novela responde al apellido de Malabre, y en la película al nombre de Sergio, coincidiendo con el del actor que lo encarna) tiene la lucidez que le confiere el cinismo. Esa distancia le permite percibir lo que otros no ven; inmersos en el proceso, pierden de vista lo que a él, en cambio, se le hace muy claro. De paso, la postura de este es un revulsivo para el lector-espectador, quien ha llegado a naturalizar una realidad a la que el personaje le descubre permanentemente las fisuras. Si bien el símbolo de la película es el telescopio a través del cual Sergio observa la realidad desde lo alto y a la distancia, no es menos cierto que su interpretación de la realidad posee, con frecuencia, más efectividad y agudeza de la que demuestran tanto los demás personajes como los espectadores.

La novela y la película cuentan, en buena medida, la historia de un escritor frustrado que escribe un diario y ha quedado solo en su país, después de que la familia y los amigos marcharan al exilio: "Todos los que me querían y estuvieron jodiendo hasta el último minuto se han ido ya" (Desnoes, 2003: 7), dice la línea que inaugura el texto. Las relaciones de ese escritor con el medio cultural habanero son más bien escasas aunque, como espectador de ese entorno, visita librerías, va a exposiciones y museos, asiste a

\footnotetext{
${ }^{3}$ Véase el reciente libro de Iván Giroud: La historia en un sobre amarillo. El cine en Cuba (1948-1964). La Habana: Ediciones Nuevo Cine Latinoamericano / Ediciones ICAIC, 2021.
} 
conferencias, ve películas. En esa misma Habana en la que circulaban también, digamos, José Lezama Lima y Virgilio Piñera, Cintio Vitier y Eliseo Diego, Guillermo Cabrera Infante y Pablo Armando Fernández, Roberto Fernández Retamar y Heberto Padilla; en ella, repito, Malabre solo "ve" a dos escritores: Carpentier y Eddy (aparte de a "dos o tres escritorzuelos" más a los que se refiere de pasada). ${ }^{4}$ Por alguna referencia podemos pensar que Malabre fue lector de Lunes de Revolución (un mal lector de Lunes, debemos suponer, dada las posiciones abiertamente revolucionarias del magacín, contrastantes con las del personaje). Sin embargo, no se trata de un diletante en el sentido de superficialidad que puede encerrar el vocablo. Malabre/Sergio procesa lo que ve y lo que lee en función de la sociedad en que vive y, como ya he dicho, es capaz de percibir lo que otros más inmersos en la realidad no alcanzan a ver. Así, esa "bomba de profundidad" que fue para él Hiroshima, mi amor, la película de Resnais, le permite reflexionar sobre uno de los síntomas del subdesarrollo cubano; la visita al Museo Hemingway, sobre la que volveré, lo motiva a pensar sobre el colonialismo; y la lectura del libro Moral burguesa y revolución, al que también me referiré más adelante, le descubre un modo de mirar la realidad desde otra perspectiva. Podría uno arriesgarse a decir que aunque la polémica en torno a P.M. y sus consecuencias eran recientes en el relato de Memorias..., ellas no aparecen de manera expresa no solo porque Malabre/Sergio no tenía relación directa con el medio intelectual, sino también porque sus preocupaciones parecían de mayor calado: le interesaba menos el rumbo de una política cultural, digamos, que el sentido de la Revolución y el destino del país.

Pese a que, como ya señalé, Memorias... elude lo festivo, el comienzo mismo de la versión cinematográfica tiene lugar en medio de un baile popular que, en cierta medida, remite a la atmósfera y al mundo de P.M. Ese espíritu de fiesta, en verdad, no se había detenido y estaba en su apogeo en la misma época en que los autores del corto pretendieron exhibirlo en un cine (pese a que el argumento oficial para la prohibición fue acusarlo de "ofrecer una pintura parcial de la vida nocturna habanera..."). "Dudo que la historia de la música cubana", ha asegurado una estudiosa, "registre tantos bailes populares masivos como los que tuvieron lugar en 1961", etapa en la que "se produce un verdadero desbordamiento de la cultura popular" (Orejuela Martínez, 2006: 172). Después de Girón (que fue precisamente el momento en que apareció P.M.), los clubes más aristocráticos del país, recién expropiados, celebraron fiestas populares sin precedentes. Sin embargo, la escena inicial de Memorias... — cuya cadencia contrasta de manera ostensible con el ritmo pausado del documental- concluye con una muerte, es decir, de forma abrupta y violenta, lo que puede remitir también al modo en que acabó la experiencia, la fiesta de P.M.

En cierto momento del largometraje el protagonista lleva a Elena, dado su interés en convertirse en actriz, a ver a un director de cine amigo suyo. El encuentro con este -interpretado por el propio Gutiérrez Alea - tiene lugar en las oficinas del ICAIC, donde el director les muestra fragmentos eróticos de viejas películas y les explica que son escenas eliminadas por la Comisión Revisora de Películas. Dicha Comisión, por cierto, fue sustituida en octubre de 1959 por la Comisión de Estudio y Clasificación de Películas, adscrita al ICAIC, encargada de autorizar y catalogar por edades los filmes que se exhibían en el país. Poco más de un año después de creada, en noviembre de 1960, un Acuerdo del Consejo de Dirección del ICAIC prohibió la exhibición, por razones políticas o estéticas, de más de noventa películas entre las centenares que inundaban las pantallas cubanas, la inmensa mayoría de procedencia norteamericana. Algunos de los títulos eliminados dan fe tanto del más rancio espíritu de la Guerra Fría (La prisionera del Kremlim, Operación Korea, Yo fui comunista para el F.B.I., La bestia de Budapest), como de la más limitada —o fértil—imaginación (El estrangulador fantasma, El monstruo del infierno verde, Invasión de discos voladores, La cabeza maléfica) (Giroud, 2021: 346-348). Esa prohibición pareció lo más natural del mundo en el contexto que se estaba viviendo, y estuvo lejos de provocar resquemores en los medios intelectuales, desinteresados en estimular el anticomunismo o en fomentar rudimentarias propuestas artísticas. Sin embargo, la decisión de dicha Comisión en torno a un corto de menos de quince minutos realizado por

\footnotetext{
${ }^{4}$ En la versión cinematográfica, como veremos, cambian (y se internacionalizan) los escritores.
} 
dos jóvenes casi desconocidos, provocó las reacciones que conocemos. De manera que cuando el personaje del director, dentro de Memorias..., alude a la censura de la vieja Comisión, el espectador avisado puede pensar en una censura mucho más reciente, no la de las noventa películas sacadas de cartelera, sino la de aquel documental. En el diálogo que se produce entre Sergio y el director amigo suyo, una vez que han visto las escenas, aquel dice, en referencia a los antiguos censores: "Parece que esa gente también tenía sus preocupaciones de tipo moral", a lo que el director responde: "Por lo menos se preocupaba de guardar las apariencias". La referencia a las "preocupaciones de tipo moral" atiende de manera más directa a la mentada polémica de 1963 que a la del corto, dos años antes, pero la presencia de esta flota en el ambiente. Inmediatamente después, cuando el director asegura —en clara mise-en-abyme — que incluirá aquellas escenas en una película que está preparando, Sergio le pregunta: “¿Te la dejarán pasar?", a lo que el otro responde con expresión divertida, más que preocupada: "Sî́". Es decir, la película que estamos viendo rescata escenas que no pudieron verse en su momento, y abre la perspectiva de que un espectador futuro pueda ser testigo del rescate de P.M.

Como sabemos, fue un largo debate de tres jornadas en la Biblioteca Nacional el que cerró, en lo inmediato, el capítulo abierto con la prohibición de P.M. En la misma sala donde tuvieron lugar aquellos diálogos, se celebra ahora una mesa sobre la novela contemporánea a la que asiste Malabre en el texto de Desnoes: "Eddy es uno de los que van a hablar [...]. Voy a ir: quiero ver qué dirá. ¿Qué puede decir sobre la novela que no esté ya dicho? Y mejor de lo que él podrá expresarlo en su puñetera vida" (2003: 51). Malabre recuerda que en otra época de su vida respetaba a Eddy porque hacía todo lo que él no se atrevía a hacer. Ahora, al terminar de leer la novela del viejo amigo, que ha comprado unos días antes en cuyo argumento es posible reconocer, aunque Malabre no la mencione por su nombre, No hay problema (1961), del propio Desnoes-, expresa: "Es de un simplismo que me ha dejado boquiabierto. Escribir eso después del psicoanálisis y los campos de concentración y la bomba atómica, es realmente patético. Yo creo que lo ha hecho por oportunismo" (2003: 50-51). Más adelante especula que si Eddy regresó a Cuba después de la revolución, fue "porque en Nueva York no era nadie: para lucirse en el subdesarrollo" (2003: 52). En ese sentido, cumplió un camino inverso a los de sus otros amigos y familiares, quienes se sienten expulsados por la Revolución. Viendo a Eddy allí, en el estrado del teatro de la Biblioteca Nacional, disertando y dándole vueltas en la boca a un tabaco, mientras habla de Joyce, Kafka y Proust, Malabre no puede sino exclamar (identificando por primera y única vez al personaje de Eddy con el autor real de la novela): “QQuién te ha visto, Eddy, y quién te ve, Edmundo Desnoes!” (2003: 53).

Coinciden con este, en la mesa, aquellos "dos o tres escritorzuelos" más a los que no vuelve a mencionar, y Carpentier, “i[...] el único escritor que no necesita de la Revolución para lucirse!". Sin embargo, Malabre se apresura a retacear su dimensión y, sobre todo, a desmarcarse de ella. "Como cronista de la barbarie americana no está mal", concede; "ha logrado sacar del subdesarrollo el paisaje y la absurda historia del Nuevo Mundo" (2003: 51-52). Pero advierte que eso no le interesa: "¡Estoy cansado de ser antillano! Yo no tengo nada que ver con lo 'real maravilloso'; no me interesan la selva, ni los efectos de la Revolución Francesa en las Antillas" (2003: 52). Paradójicamente, es la Revolución la que empuja a Malabre a sentirse como una suerte de "ciudadano del mundo", posición desde la que le resulta estrecha la noción de antillanidad que construye Carpentier. Hay en ese pasaje, por cierto, un anacronismo, puesto que son bastante obvias en las palabras del personaje las referencias a El reino de este mundo, Los pasos perdidos y El siglo de las luces. Sin embargo, esta última no apareció en Cuba sino en agosto de 1963 (aunque tuvo antes una edición mexicana), o sea, varios meses después del momento en que se desarrolla Memorias... Lo interesante es que, para remarcar su distancia con la novela de Carpentier, Malabre se concentra en su costado antillano, y desecha el que pudiera haberle sido más provechoso: el de la ambigua interpretación que la novela propone sobre el curso y sentido de las revoluciones.

En la versión cinematográfica la mesa redonda cambia de tema y de protagonistas, a tono con la mayor politización y radicalidad de la versión de Alea, y aprovechando la presencia de ellos en el Congreso Cultural de La Habana, en enero de 1968. En lugar de "la novela contemporánea", el tema que reúne 
ahora a los ponentes es "Literatura y subdesarrollo", sobre el que disertan el haitiano René Depestre, el italiano Gianni Totti, el argentino David Viñas y el propio Desnoes. Al final de las intervenciones y desde el público, el dramaturgo Jack Gelber — quien, por cierto, había prologado la edición en inglés, publicada en Nueva York en 1967- hace la siguiente pregunta: "Siendo la Revolución cubana una Revolución original, ¿por qué recurre a métodos convencionales como son las mesas redondas?, ¿por qué no desarrolla un método más dinámico de establecer una relación entre el panel y el público?”. Pudiéramos forzar una interpretación de tales interrogantes. Ese "método más dinámico" que extraña Gelber fue precisamente el que se desarrolló en las reuniones que tuvieron lugar en esa misma sala en junio de 1961 (lo que, a los efectos de la película, supone que ocurrieron pocos meses antes). Gelber apela a un diálogo más directo e inmediato y, sin proponérselo, nos devuelve a la circunstancia anterior. De ese modo, el espacio que había servido para dirimir y cerrar en lo inmediato la disputa en torno a P.M., sirve ahora de escenario para retomar la discusión en torno al tema, desde otro punto de la historia.

\section{Dos}

Mes y medio después de la muerte de Ernest Hemingway, Lunes de Revolución le dedicó un númerohomenaje (el 118, del 14 de agosto de 1961). Era una muestra de la admiración que sentían los escritores cubanos por uno de los más notables narradores del siglo XX, quien escribió o ubicó en la Isla algunas de sus más célebres historias. Además de esa lealtad a Cuba, que se vio exacerbada después del triunfo de los barbudos (basta ver, para confirmarlo, el texto de Cabrera Infante en aquel número de Lunes: "Hemingway y Cuba y la Revolución"), el autor de El viejo y el mar tenía un atractivo adicional para los escritores cubanos. La potencia antintelectual del personaje que él hizo de sí mismo resultaba particularmente seductora para aquellos. En un momento en que la Revolución cubana pedía de sus intelectuales algo más (mucho más) que labores propias de la creación artístico-literaria y del pensamiento; cuando los convocaba a participar en tareas que implicaban poner el cuerpo, Hemingway parecía un ejemplo digno de tener en cuenta.

Entre los textos incluidos en esa entrega de Lunes se encuentra el de Edmundo Desnoes, "Lo español en Hemingway", clara muestra de la devoción de su autor por el escritor recién desaparecido. En su largo elogio reconoce, sí, que pueden existir "granos de superficialidad" en el acercamiento de Hemingway a nuestra cultura (entendiendo como tal la cultura hispánica), pero su muerte y el análisis minucioso de su obra, opina Desnoes, desmienten en gran medida esta conclusión, pues aquel "amó profundamente a los hispanos y a todas sus manifestaciones" (1961: 14). Desnoes reconoce que junto al genuino amor del norteamericano por nuestra cultura y nuestros pueblos, una veta de desprecio atraviesa algunas de sus obras. Lo salva, sin embargo, recordando que "hasta el sol tiene manchas, como dijo Martí", y que era "un hombre con contradicciones profundas que nunca ocultó" (1961: 15). Bastó un lustro para que la imagen de Hemingway se modificara radicalmente, y nadie hizo más por ello, al menos en Cuba, que el propio Desnoes en el ensayo "El último verano", publicado originalmente en la revista mexicana Siempre! (14/11/1966) y recogido en el volumen Punto de vista (1967), así como en el guion de la película y en la segunda edición de la novela, que incorporaron varias de las ideas del ensayo. No fue un giro casual porque lo cierto es que en esos pocos años el mundo, visto desde Cuba, había dado un giro profundo.

Un texto intermedio de Desnoes, su prólogo de 1964 a la edición cubana de Retrato del artista adolescente, la cual revisa la traducción de Dámaso Alonso de 1926, da fe de aquel giro. En ese prólogo, Desnoes saca a Joyce de la tradición eurocéntrica y lo reinscribe en la historia colonial y postcolonial irlandesa, lo que sería válido para la realidad y los escritores hispanoamericanos en general, y cubanos en particular. Según César A. Salgado, esa interpretación política y estética de Joyce como un intelectual subalterno de la periferia colonial reemplaza el retrato que hace su biógrafo, Richard Ellmann, de Joyce 
como un escritor exiliado, formalista, e identificado con el cosmopolitismo metropolitano. Desnoes usa a Joyce - el único de los grandes escritores de la vanguardia que encara los problemas de la soberanía nacional y el subdesarrollo, según él— para ilustrar los dilemas que los intelectuales progresistas de la periferia, que trabajan en condiciones de subdesarrollo económico y cultural, confrontan cuando se rebelan contra los valores e instituciones hegemónicas (Salgado, 2014: 122). Para Salgado, de hecho, la recanonización propuesta por Desnoes en 1964, anticipó la interpretación postcolonial de Joyce entre los académicos durante la década de los noventa (2014: 123). Es en ese contexto intelectual que Desnoes recoloca la figura de Hemingway vista desde (la nueva) Cuba. ${ }^{5}$ En ese punto, y pese a las notables diferencias entre ambos, son evidentes las semejanzas entre las posiciones de Desnoes y las de su personaje novelesco. En verdad, mientras Desnoes escribía para el homenaje de Lunes ese retrato admirativo y conciliador que es "Lo español en Hemingway", su personaje ve lo que él no pudo percibir entonces. Es decir, el autor pondrá en boca de este — cuyo presente transcurre en 1961-1962_, lo que él mismo fue incapaz de ver en ese momento. Fueron necesarios varios años, ciertos acontecimientos y varias sacudidas para que el autor real sintiera una distancia inconmensurable de sus antiguas opiniones sobre Hemingway: "su realidad hace mucho tiempo que pasó para mí; siglos. Los siglos que representan siete años de revolución” (Desnoes, 1967: 53).

"El último verano" se detiene en el análisis de ciertas piezas del escritor norteamericano ("Nosotros salimos muy mal parados en la obra de Hemingway. No nos engañemos"; Desnoes, 1967: 51), y añade algo útil para entender algunas zonas de la mirada del protagonista de Memorias...: "Elegancia y estilo no son cosas para nosotros, de nuestro mundo. Nosotros no somos elegantes ni tenemos estilo, somos ignorantes y groseros porque somos pobres, nos han mantenido pobres los del mundo industrializado que glorifica la obra y la vida de Hemingway". Y remata afirmando que al glamour estudiado de Hemingway oponemos nuestro incontenible caos (1967: 51). El ensayo alude también a la visita al Museo Hemingway en Finca Vigía, que ocupará una docena de páginas de la novela y varios minutos en la película. Desnoes reconocería en dicho ensayo que, en Cuba, Hemingway "vivió como un inglés retirado en una de sus colonias, con simpatía por el pueblo cubano, pero mirándolo desde arriba, desde la Vigía" (Desnoes, 1967: 38). Son obvias, en estos comentarios, las semejanzas entre el dueño de Finca Vigía y el protagonista de Memorias...; ambos "glamorosos", ambos distantes. ${ }^{6}$ Sin embargo, una vez establecidas tales coincidencias, digámoslo así, clasistas, comienzan las diferencias.

Y la diferencia mayor es entre la perspectiva del colonizador y la del colonizado. Hemingway representaría al primero, mientras "nosotros" ocuparíamos el lugar del segundo. Y en ese nosotros caben lo mismo el protagonista de Memorias... que René Villarreal, el hombre de confianza del escritor en la Finca, el niño negro recogido años atrás, el único que podía entrar a la habitación cuando Hemingway escribía porque no hacía ruido. Podemos verlo en la película en el papel de guía del Museo, y las reflexiones de Malabre/Sergio son muy similares a las de Desnoes en "El último verano". Para este, "la revolución ha roto para siempre la posibilidad de que una relación semejante vuelva a producirse en Cuba. [...] No seremos más criados de amos extranjeros, aunque esos amos nos ayuden a vivir con comodidad, nos sienten a su mesa, nos tengan protegidos por las violentas luchas de nuestra época. Nada. La dignidad se paga caro" (Desnoes, 1967: 47). Para el personaje de la novela y la película, por su parte, Hemingway "amoldó [a Villarreal] a sus necesidades, el criado fiel perro del gran señor. El colonizador y Gungha Din” (2003: 41).

Por otra parte, si a Desnoes se le hace evidente, después de recorrer la casa, "que Cuba no ha dejado allí ninguna huella. [...] Como si la casa estuviera en la Florida, Birmania o las Filipinas" (1967:

\footnotetext{
5 En 1979 Desnoes le respondía a William Luis: "Después de 1961 hubo otra etapa; escribí Memorias: es la etapa de la Tricontinental y de la lucha armada. Por eso la llamé Memorias del subdesarrollo —un análisis de la mentalidad del colonizado..." (Santí, 2002: 289n).

'Santí hará notar que "al igual que Hemingway, Malabre ve a Cuba desde la segura distancia de una torre enajenada [...]" (2002: 292).
} 
46), Malabre descubre en su recorrido "que Cuba no le interesó nunca ni un carajo a Papa Hemingway. [...] En toda la casa no había nada cubano, ni un objeto de santería o un cuadro. Nada. Cuba, para Hemingway, era un lugar para refugiarse, vivir tranquilamente con su mujer, recibir a sus amigos, escribir en inglés, pescar en la Corriente del Golfo" (2003: 47). Resulta curioso, asimismo, que la opinión del Desnoes ensayista sea no solo avalada por ese conflictivo alter ego suyo que es Malabre, sino también por Elena, la joven superficial e ignorante con la que este mantiene una relación a pesar de la abismal diferencia intelectual entre ambos. Si en el ensayo se afirma que "[d]e primer golpe [Finca Vigía] nos parece la residencia de cualquier administrador norteamericano de ingenio azucarero [...]" (1967: 46), Elena, aun en su rusticidad, percibiría algo similar: “¿Aquí vivía el míster Way ese? Yo no le veo nada del otro mundo a esta casa, la verdad, libros y animales muertos. Buena mierda. Se parece a la casa de los americanos del central Preston" (2003: 38). Es decir, frente al "enemigo" común, la mirada de Elena y de Malabre/Sergio coinciden. Él desde la intelección, ella desde el hastío, ven en Hemingway al "otro" que los desdeña.

Desnoes transita incluso del tema de la descolonización al de la expropiación. Recuerda en su ensayo que a mediados de 1960 Hemingway empezó a planear su retirada de Cuba y que entonces salieron del país más de un millón de dólares en cuadros. Si Malabre echa en falta la obra de Miró que se llevó Miss Mary, como todos las demás, a cambio de la promesa de enviar reproducciones ("Eso es lo que merecemos, copias"), Desnoes es mucho más radical: "yo jamás hubiera permitido sacar[las]", dice. Y añade: "La revolución fue demasiado generosa. Esos cuadros estarían mejor en el Museo Hemingway o el Museo de Bellas Artes de La Habana. Somos también demasiado pobres en obras de calidad y si hemos nacionalizado bancos, muy bien podríamos nacionalizar cuadros" (1967: 55). Y en su tarea de demolición del pedestal sobre el que los escritores cubanos mantuvieron a Hemingway, Desnoes recuerda una escena que le resulta reveladora. Aunque el autor norteamericano no tuvo para la Revolución cubana, al menos de manera pública, sino elogios, Desnoes nos recuerda su opinión "sobre las revoluciones, expresada mientras conversaba con las verdes colinas de África al fondo: 'Son bellas. De verdad. Por un tiempo. Luego se echan a perder" (1967: 56).

\section{Tres}

Hay en Memorias del subdesarollo dos lecturas "raras" por parte de su protagonista. Raras en el sentido de que no coinciden a simple vista con la ideología del personaje y que demuestran, a la vez, su amplitud de miras. La primera es Hacia la estación de Finlandia, que Malabre le recomienda a su amigo Pablo: "Le di To the Finland Station, de Edmund Wilson, para que tuviera aunque sea una noción del desarrollo de las ideas sociales, del socialismo, desde la Revolución Francesa hasta la Revolución Rusa. Estoy seguro de que ni lo abrió cuando llegó a la casa" (2003: 19). Lo extraño no es solo que le recomiende tal libro a una persona de una simpleza sobrecogedora y ajena a cualquier idea medianamente revolucionaria, sino incluso que a él mismo le parezca recomendable. No hay que pasar por alto de que para entonces no era conocida, obviamente, la "Introducción de 1971", en la que Wilson incluyó "ciertas correcciones y modificaciones con el fin de rectificar una visión demasiado optimista por mi parte" (2011: 11). Esa relectura un tanto desencantada de la historia, que el propio Wilson realizaría años después, habría explicado en mejor medida el interés de Malabre en el libro, un poco más cercano, ahora, a su visión del mundo.

Me interesa detenerme, sin embargo, en la segunda lectura. Esta — a diferencia de aquella, que solo se menciona en la novela - aparece exclusivamente en la versión cinematográfica, donde adquiere especial relevancia. Se trata de Moral burguesa y revolución, de León Rozitchner, volumen publicado en Buenos Aires por la editorial Procyon en 1963, que Sergio compra en una librería habanera. El análisis de Rozitchner toma como punto de partida los interrogatorios a los prisioneros de guerra capturados tras 
la invasión por Bahía de Cochinos el 17 de abril de 1961. Derrotados el día 19 en Playa Girón, fueron siendo apresados o se rindieron en masa. A partir del 21 de abril, varios de ellos comparecieron de forma voluntaria ante la prensa. Esos interrogatorios fueron trasmitidos en directo por radio y televisión, y reproducidos textualmente en los periódicos, y permitieron confrontar de manera pública e inmediata a derrotados y vencedores. Basándose en aquellos diálogos, Rozitchner expuso en su análisis las contradicciones morales de los invasores y abordó, a partir de sus declaraciones, las divergencias entre lo que aquellos representaban y el discurso revolucionario al que se enfrentaban. El muy posterior ensayo de Hans Magnus Ensenzberger — deudor en toda la línea del libro de Rozitchner- titulado "El interrogatorio de La Habana" asegura que dicho interrogatorio — que "no sólo nace de una situación revolucionaria, sino que es por sí mismo un acto revolucionario" sin equivalente en Europa- "no tiene por meta obtener una confesión, sino trazar un autorretrato. Más concretamente, el autorretrato de una clase social" (1973: 24).

Según Rozitchner, la finalidad de su trabajo es "[e]nfrentar las concepciones morales de la burguesía con la ética de la Revolución” (2012: 25) apelando a las intervenciones de quienes reivindicaban la acción que los llevó al combate, "reiterándola en las palabras", que era para los prisioneros una manera de continuar así su lucha (2012: 26). Tal vez la parte más sobresaliente del libro del argentino, y la que sin duda más impacto tuvo y más comentada ha sido, es la titulada "La verdad del grupo está en el asesino". De ese capítulo, en la película, se escuchan fragmentos leídos o adaptados por Sergio, en off, mientras pasan ante nuestros ojos imágenes documentales. Lo que Rozitchner señala allí es el hecho de que el grupo invasor "encierra una jerarquía de funciones, dependientes las unas de las otras", que compendia "la estructura del poder de la burguesía: el religioso, el hombre de la libre empresa, el militar, el torturador, el diletante, el filósofo racionalista, el político y los hijos de buenas familias" (2012: 95). El grupo se mueve entre dos polos: el espiritual del sacerdote y el material del asesino. Este es el caso de Calviño, "un criminal que hasta a los mismos burgueses causa horror y desprecio. Pero fue solicitado por la misma burguesía para cumplir su tarea [...]. Calviño, como asesino, era aquel individuo al cual una colectividad le había señalado las tareas más miserables, pero necesarias, de su sistema de existencia" (2012: 99). Su trabajo, en pocas palabras, era necesario para sostener "la existencia de aquellos que no están en contacto directo con la muerte que suscitan, y que por haber realizado implícitamente esa delegación pueden ostentar, como individuos separados, sus almas limpias. Pero todos se deben mutuamente la vida" (2012: 101). Es decir, si bien todos los miembros del grupo invasor dan la espalda a Calviño una vez que han sido vencidos y reivindican la decisión de participar en la expedición a título personal, es el asesino quien se reconoce como parte de un grupo e intenta darle coherencia a la totalidad. Es él, entre todos los interrogados, quien provoca las reacciones más fuertes desde el punto de vista emotivo y quien ocupa mayor espacio en el filme.

Sin embargo, quisiera rescatar la intervención de otro de los prisioneros: Felipe Rivero Díaz, mencionado en el libro de Rozitchner como "el diletante" y en la película como "el funcionario diletante" y "el diletante Rivero". Dentro de los interrogatorios, su intervención fue, con mucho, la que más espacio ocupó y la más interesante de todas. Resultó ser, además, la que más exigió de sus interlocutores. Sus palabras no encierran, desde luego, el dramatismo de la confrontación con Calviño, pero provocan y exigen mayor reflexión. Al mismo tiempo, Rivero guarda no poco parecido con Sergio. Digamos que, si Rivero hubiera permanecido en Cuba, habría sido como Sergio. Casi al final del intercambio con él durante el interrogatorio, Carlos Rafael Rodríguez (entonces director del periódico Hoy) le preguntó por qué no había regresado a su país en son de paz: "Aquí hay centenares de personas como usted, señor Rivero, que piensan como usted, hablan como usted en las calles, y no les ha pasado nada" (Otero, 1962: 229). Es fácil imaginar que una de esas centenares de personas podría ser el protagonista de Memorias...

\footnotetext{
${ }^{7}$ Ese es, de hecho, el título de una de las primeras reseñas que se le dedicó, la de Jesús Díaz en Casa de las Américas 31 (1965): 96-98, así como da nombre a una de las partes del filme.
} 
Heredero de una familia rica, Rivero se reconoce como nacionalista y no duda en afirmar que está "plenamente de acuerdo [con] que debe irse a una repartición más justa de las riquezas" (Otero, 1962: 198). De hecho, asegura que, de triunfar la invasión, su idea era tal vez fundar un partido político que buscara la tercera posición, a la manera de Nasser en Egipto, no alineado con los soviéticos ni con los norteamericanos. Dicho así suena irónico, dado que fue a la sombra de estos que Rivero invadió su país, pero aun en ese caso se aparta de las posiciones de la mayor parte de sus compañeros de expedición. El que más se esmera en hablar a título personal es precisamente Rivero, y pretende hacerlo sosteniendo una conversación de igual a igual, en el terreno intelectual, con sus interlocutores. Quiere que se note que está muy por encima del resto de los invasores. No duda, por ejemplo, en reconocerse como cínico, disertando ampulosamente: "El cinismo es decir lo que muchos piensan y no se atreven a decirlo. Usted sabe bien que los discípulos de Antístenes no son como los ve el vulgo, o no es lo que quiere decir el vulgo, el cínico no es un tipo ordinario grotesco, ni mostruoso..." (Otero, 1962: 223). Desde mucho antes, desde el comienzo del diálogo, Rivero había reconocido que también era escritor, que "escribía por "hobby"' (Otero, 1962: 197), y que hacía años había publicado un libro. Se refiere, aunque no lo mencione de manera explícita, a Diario de un día, publicado por la Editorial Lex en 1950.

La estructura externa de ese libro, por cierto, es bastante similar a la de Memorias...: una novela corta y homónima que precede a varios cuentos. En el caso de la novela de Desnoes es la incierta escritura de un diario la que sostiene tanto intelectual como personalmente al protagonista, lo único que parece llenar el vacío en que se ha convertido su existencia. Hay que recordar que parte de su rutina es caminar por La Habana, solo para descubrir que "parece ahora una ciudad del interior [...]. Ya no parece el París del Caribe, como decían los turistas y las putas. Ahora parece más bien una capital de Centroamérica, una de esas ciudades muertas y subdesarrolladas, como Tegucigalpa, o San Salvador o Managua" (2003: 11). Ese rechazo a la nueva realidad y a sus protagonistas, sin embargo, no es menor que el desprecio que el personaje siente por su propia clase, de manera que no resulta raro escucharle: "Eso es lo único que tengo que agradecerle a la Revolución: haber jodido a los cretinos que mangoneaban todo aquí!” (2003: 17); o "[n]o puedo pensar en la burguesía cubana sin echar espuma por la boca. Los odio tiernamente. Me dan lástima: por lo que pudieron haber sido y no fueron por imbéciles" (2003: 18); o "la Revolución, aunque me destruya, es mi venganza contra la estúpida burguesía cubana, contra mi propia vida cretina" (2003: 26).

Leída después del Diario de un día, de Rivero, no podemos dejar de sentir ciertas resonancias de ese texto en Memorias... Aquella novela mediocre y casi desconocida es, sin duda, un antecedente de la de Desnoes. Como indica su título, cuenta la historia de un día de Ricardo, su narrador-protagonista. Al igual que Malabre, al igual que Rivero, el personaje de su novela es un cínico absoluto, que desprecia a todos, tanto a los que están por debajo de él en la escala social como a los burócratas, o incluso a los de su propia clase. Las conversaciones con sus amigos recuerdan con frecuencia las de Malabre/Sergio con Pablo en Memorias... Considera a sus amigas unas "imbéciles" (Rivero Díaz, 1950: 51), y describe a los clubmen como un grupo, "formado en su mayoría, por seres cuya personalidad estribaba en el club a que pertenecían, el costo de su automóvil y las propiedades de su familia" (1950: 52). Y se permite citar a Marx sin sobresalto. A semejanza del personaje de Desnoes, el protagonista de Rivero se reconoce "alérgico a las multitudes" (1950: 55). Una larga escena es reveladora tanto del personaje como de su visión de la sociedad en la que vive. Es útil detenernos en ella porque se revelan claramente en ese pasaje tanto la filosofía del propio Rivero en el interrogatorio de 1961, como innegables similitudes con el protagonista de Memorias..., que bien pudo — en su lugar- haber dicho algo semejante.

Una noche, al pasar "junto a un parque por lo general sumido en tinieblas", Ricardo lo ve "iluminado y profusamente adornado de banderolas y pasquines". La "enorme y abigarrada multitud se apretaba en torno a una grotesca tribuna", "sobre la cual gesticulaba un individuo frente a un improvisado micrófono". Detrás de él, otros "se movían nerviosos y daban órdenes, no se sabe a quién. Una bandera nacional, con expresión cansada adornaba el frente de la tribuna, voladores y triquitraques completaban 
el cuadro...". Ante tan deprimente cuadro, el narrador no duda en afirmar: "Era un 'mitin' político" (1950: 83). Ricardo descubre en el lugar a "chiquillos harapientos atraídos por las luces", y a adultos no más inteligentes que ellos. De lo que dijo con voz gangosa el "burdo intento de Demóstenes" que ocupaba la tribuna, "sólo pude captar la palabra Democracia; creo que la escuché dos o tres veces sólo en el tiempo que me tomó cruzar frente al lugar donde se celebraba el acto". Entonces el personaje reconoce: "No puedo negar que odio a esa palabra y todo lo que ella representa, por lo menos lo que de ella he visto hasta ahora. No soy político ni quiero dármelas de filósofo, pero me parece una grotesca mentira, una nauseabunda vOz, una palabra obscena que repiten sin descanso un sinfín de mediocres a una multitud también de mediocres" (1950: 84). Piensa entonces con asco que si bien él mismo no trabajaba y podía ser considerado un parásito, al menos nadie "me podrá echar en cara que milito en ninguna de estas asquerosas aglomeraciones que se denominan a sí mismas partidos políticos" (1950: 8586), y reconoce como una mentira que en un régimen democrático los más altos cargos estén al alcance de todos, pues solo acceden a ellos quienes "tengan el dinero suficiente para pagar su propaganda", sin importar "su condición moral, ni la ideología que sustenten". Comenta, además, que aparte de los comunistas los otros partidos políticos se diferencian únicamente en sus nombres, todos manchados por alianzas absurdas y compromisos escandalosos. Incluso los comunistas, dice, se han tenido que valer de semejantes prácticas, pero hay que reconocer que son los "de más pura esencia idealista"; y cómo no iban a serlo, "si los otros no conocen ni remotamente lo que es un ideal" (1950: 87-88). Finalmente resume: "ya que por el momento somos impotentes de organizarnos en algo distinto a todo esto, abstengámonos por lo menos de tomar parte en esta farsa tan vil que se llama democracia” (1950: 88).

Podemos conjeturar que Rivero (la persona concreta que habla en el interrogatorio después de Playa Girón), su protagonista Ricardo y el Malabre/Sergio de Memorias... pudieran ser en cierto sentido el mismo personaje, aunque las opciones que asumen el primero y el último sean opuestas. En cuanto a Ricardo, desconocemos su destino. Es fácil imaginar que de ninguna manera se hubiera "integrado" a la Revolución, pero ante sí — desde el punto de vista de nosotros, los lectores de hoy- parecen dibujarse dos destinos posibles: el de su autor, es decir, el del exiliado temprano que, haciendo a un lado su obvio desinterés por la política, regresa en una invasión contra el país natal, o el de quien se queda en el país, como en el caso de Malabre/Sergio, intentando mantenerse — en precario equilibrio — al margen de la historia.

Lo curioso es que ese intelectual "por cuenta propia" que circula al margen (también) de la institucionalidad literaria ejemplifica parte de las tensiones que vivieron incluso los intelectuales orgánicos en aquellos momentos iniciales de toda una sociedad tras el triunfo de 1959. Malabre/Sergio no hace sino llevar al límite, en ocasiones hasta el absurdo, preguntas e inquietudes que debieron responderse a sí mismos los escritores que sí se sumaron a la marea revolucionaria. En ese sentido, Memorias del subdesarrollo puso a los intelectuales cubanos (a Desnoes y Alea, en primer lugar) frente a un espejo que les mostraba sus propias contradicciones.

\section{Bibliografía}

DeSNOES, Edmundo (1961), "Lo español en Hemingway”, en Lunes de Revolución, n. 118, pp. 14-15.

Desnoes, Edmundo (1967), Punto de vista. La Habana, Instituto del Libro.

DeSNOES, Edmundo (2003), Memorias del subdesarrollo. La Habana, Editorial Letras Cubanas.

ENSENZBERGER, Hans Magnus (1973), "El interrogatorio de La Habana", en El interrogatorio de La Habana. Autorretrato de la contrarrevolución y otros ensayos políticos. Barcelona, Anagrama, pp. 9-55. 
GIROUD, Iván (2021), La bistoria en un sobre amarillo. El cine en Cuba (1948-1964). La Habana, Ediciones Nuevo Cine Latinoamericano / Ediciones ICAIC.

Guevara, Alfredo (2003), Tiempo de fundación. Madrid, Iberautor Promociones Culturales.

GuTIÉRREZ ALEA, Tomás (2007), Volver sobre mis pasos. Mirtha Ibarra (sel.). Madrid, Ediciones Autor.

LUIS, William (2003), “Lunes de Revolución”. Literatura y cultura en los primeros años de la Revolución Cubana. Madrid, Editorial Verbum.

Orejuela MartínEZ, Adriana (2006), El son no se fue de Cuba: Claves para una historia 1959-1973. La Habana, Letras Cubanas.

Otero, Lisandro, Edmundo Desnoes y Ambrosio Fornet (eds.) (1962), Playa Girón: derrota del imperialismo. La Habana, Ediciones R, vol. 4.

Paz, Senel (sel.) (2021), Aquel verano del 61. Primer encuentro de Fidel con los inteletuales cubanos. La Habana, Ediciones ICAIC.

PogolotTi, Graziella (sel. y pról.) (2006), Polémicas culturales de los 60. La Habana, Editorial Letras Cubanas.

Rivero Díaz, Felipe (1950), Diario de un día. La Habana, Editorial Lex.

ROZITCHNER, León (2012), Moral burguesa y revolución. Buenos Aires, Biblioteca Nacional.

SALGADO, César A. (2014), "Detranslating Joyce for the Cuban Revolution: Edmundo Desnoes's 1964 Edition of Retrato del artista adolescente", en TransLatin Joyce. Global Transmissions in Ibero-American Literature. Brian L. Price, César A. Salgado y John Pedro Schwartz (eds.). Nueva York, Palgrave Macmillan.

SANTÍ, Enrico Mario (2002), "Ideología: Memorias del subdesarrollo", en Bienes del siglo. Sobre cultura cubana. México, FCE, pp. 278-296.

SORIANO, Leonardo/Jaime (2018), Cuba no existe o quién sabe qué propósito. Carlos Velazco (sel., pról. y notas). Miami, Editorial Silueta.

WiLSON, Edmund (2011), Hacia la estación de Finlandia. Ensayo sobre la forma de escribir y hacer historia (1940). R. Tomero, M.F. Zalén y J.P. Gortázar (trads.). Barcelona, RBA Libros. 